\title{
Pregnancy blockage and the memory of the stud male in the vole (Microtus agrestis)
}

\author{
S. R. Milligan \\ Department of Physiology, University of London King's College, Strand, \\ London WC2R $2 L S, U . K$.
}

\begin{abstract}
Summary. When female voles were allowed contact with the stud male for only $1 \mathrm{~h}$ at the time of mating, $55 \%$ exhibited pregnancy failure when exposed to a strange male $48 \mathrm{~h}$ later. When females were made pseudopregnant by hormone treatment and vaginal stimulation (i.e. no stud male involved), $87 \%$ exhibited luteal failure when exposed to a strange male. It is suggested that the characteristics of the stud male are rapidly imprinted upon the female at the time of mating and that this imprinting is important in preventing the female showing a blocking response to this male upon any subsequent exposure.
\end{abstract}

\section{Introduction}

One of the most interesting phenomena in which rodent pheromones have been implicated is the failure of pregnancy in a high percentage of newly mated females upon their exposure to a 'strange' male (i.e. a male other than the stud). The effect is primarily due to a failure of luteal function (Dominic, 1970; Milligan, 1976b) and can also be demonstrated in pseudopregnant females (Dominic, 1966). The phenomenon was first observed in the mouse (Bruce, 1959), but has since been demonstrated in the deermouse (Peromyscus maniculatus: Eleftheriou, Bronson \& Zarrow, 1962) and a number of microtine species (Clulow \& Clarke, 1968; Clulow \& Langford, 1971; Stehn \& Richmond, 1975; Mallory \& Brooks, 1978). Pheromones in the urine are believed to be the effective stimuli mediating the response in mice (Dominic, 1966), although whether the same is true for other species is uncertain. The vole, Microtus agrestis, certainly differs from the mouse in that unrestricted contact between the female and strange male is required for the effect (Milligan, 1976a). Regardless of the cues involved, however, the different responses of the female to the stud and strange male implies that the female can remember, and therefore recognize, the stud male. In view of the well defined stimulus and response parameters of male-induced pregnancy failure, it seems surprising that so little attention has been paid to the characteristics of this memory system. This paper reports a study in voles to determine the time required for the female to acquire the memory of the stud male. In addition, since pseudopregnancy may be induced experimentally without the intervention of a male (Milligan, 1975), such pseudopregnant females were used to investigate how important a memory of the stud male is in determining the blocking effect of strange males.

\section{Methods and Results}

Laboratory bred voles from the colony at King's College were maintained as described by Milligan (1974). Females were 2- to 4-month-old virgins and the males were breeding adults. 


\section{Experiment 1}

Females which mated within $30 \mathrm{~min}$ of their introduction between 09:00 and 12:00 h to a clean cage containing a male were allowed to remain with the male for a total period of $1 \mathrm{~h}$. After 2 days, the mated females were transferred to another clean cage containing either the original stud male or a strange male and were left with this male for $24 \mathrm{~h}$. A further group of females was mated as above, but the females were left with the stud male for the 2 days before exposure to a strange male on the 3 rd day. All females were examined for the presence of implantation sites on the 8th day after mating.

Of the females that were left with the stud male for only $1 \mathrm{~h}$ at the time of mating, $16 / 19$ $(84 \%)$ remained pregnant after their re-exposure to the stud male on the $3 \mathrm{rd}$ day, while only $9 / 20$ $(45 \%)$ were pregnant after exposure to a strange male $\left(\chi^{2}=6.51 ; P<0.02\right)$. Increasing the time spent with the stud male did not significantly affect the number of females remaining pregnant after exposure to a strange male $\left(12 / 16=46 \% ; \chi^{2}=0.006 ; P>0.05\right)$.

\section{Experiment 2}

Pseudopregnancy was induced in female voles by the subcutaneous injection of $200 \mathrm{ng} \mathrm{LH}$ RH (Hoechst U.K. Ltd) followed by mechanical stimulation of the vagina and cervix with a motor-driven rod (Milligan, 1975). Females were either caged with a male for 2 days beginning on the 2nd day after mating, or were left alone. All females were laparotomized 5 days after mating for examination of the ovaries (Milligan, Charlton \& Versi, 1979).

Degenerating corpora lutea were found in $13 / 15(87 \%)$ of the females that were caged with the male for 2 days, but in only $3 / 16(19 \%)$ of the control females $\left(\chi^{2}=14 \cdot 3 ; P<0.001\right)$. The remaining females in each treatment possessed functional $\mathrm{CL}$.

\section{Discussion}

The results from Exp. 1 differ from those reported for mice by Lott \& Hopwood (1972). These authors observed that the incidence of pregnancy blockage was considerably lower in females that had been exposed to the stud male for only a short period $(3 \mathrm{~h})$ as compared to those exposed for longer $(24 \mathrm{~h})$. It was suggested that this was consistent with the hypothesis that the females gradually become responsive ('sensitized') to the blocking stimuli of strange males through exposure to the stud male (Lott \& Hopwood, 1972). Although the occurrence of pregnancy blockage in voles, even when associated with only a very short exposure to the stud male (Exp. 1), might be due to a different time course of the sensitization process in this species, the results from Exp. 2 argue against this. Since the females in this experiment had not been exposed to a stud male, the blocking effect of male voles would not seem to be dependent on stimuli provided by a male at the time of the induction of ovulation and luteal activity. Instead, it is possible to suggest that all males are potentially able to block pregnancy, but that the normal lack of effect of the stud male is due to the female's recognition of this male through the imprinting which occurs at the time of mating.

I am grateful to Mr Mike Tarlton for his assistance and to Hoechst U.K. Ltd for their gift of LH-RH. This work was supported by a grant from the Medical Research Council.

\section{References}

Bruce, H.M. (1959) An exteroceptive block to pregnancy in the mouse. Nature, Lond. 184, 105.

Clulow, F.V. \& Clarke, J.R. (1968) Pregnancy block in
Microtus agrestis, an induced ovulator. Nature, Lond. 218, 511.

Clulow, F.V. \& Langford, P.E. (1971) Pregnancy block 
in the meadow vole, Microtus pennsylvanicus. $J$. Reprod. Fert. 24, 275-277.

Dominic, C.J. (1966) Observations on the reproductive pheromones of mice. I. Source. J. Reprod. Fert. 11, $407-414$.

Dominic, C.J. (1970) Histological evidence for the failure of corpus luteum function in the olfactory block to pregnancy in mice. J. Anim. Morph. Physiol. 17, $126-130$.

Eleftheriou, B.E., Bronson, F.H. \& Zarrow, M.K. (1962) Interaction of olfactory and other environmental stimuli on implantation in the deermouse. Science, N.Y. 137, 764 .

Lott, D.F. \& Hopwood, J.H. (1972) Olfactory pregnancy-block in mice (Mus musculus): an unusual response acquisition paradigm. Anim. Behav. 20, 263-267.

Mallory, F.F. \& Brooks, R.J. (1978) Infanticide and other reproductive strategies in the collared lemming, Dicrostonyx groenlandicus. Nature, Lond. 273, 144146.
Milligan, S.R. (1974) Social environment and ovulation in the vole, Microtus agrestis. J. Reprod. Fert. 41, $35-47$.

Milligan, S.R. (1975) Mating, ovulation and corpus luteum function in the vole, Microtus agrestis. $J$. Reprod. Fert. 42, 35-44.

Milligan, S.R. (1976a) Pregnancy blocking in the vole, Microtus agrestis. I. Effect of the social environment. J. Reprod. Fert. 46, 91-95.

Milligan, S.R. (1976b) Pregnancy blocking in the vole Microtus agrestis. II. Ovarian, uterine and vaginal changes. J. Reprod. Fert. 46, 97-100.

Milligan, S.R., Charlton, H.M. \& Versi, E. (1979) Evidence for a coitally induced 'mnemonic' involved in luteal function in the vole, Microtus agrestis. $J$. Reprod. Fert. 57, 227-233.

Stehn, R.A. \& Richmond, M.E. (1975) Male induced pregnancy termination in the prairie vole, Microtus ochrogaster. Science, N.Y. 187, 1211-1213.

Received 16 February 1979 